\title{
PATHOLOGICAL APPROACH TO HUMAN RESOURCE MANAGEMENT: STRATEGIC APPROACH TO MAINTENANCE HUMAN RESOURCE AND ORGANIZATIONAL COMMITMENT
}

\author{
Akram Ahmadnia Chenijani $^{\mathrm{a} 1}$, Nour Mohammad Yaghoubi ${ }^{\mathrm{b}}$ \\ a. University of Sistan and Baluchestan,Iran \\ b. University of Sistan and Baluchestan,Iran
}

\begin{abstract}
The aim of the present study is the pathological status of strategic approach to maintenance human resource and organizational commitment with checking the status of mediator variables impact on organizational commitment among organizational support, organizational justice, organizational culture and needs of Excellence. The research type is descriptive. In order to realize this, Zahedan Municipal employees, up to 2032 were considered as a statistical population, so Morgan table has been applied and 234 employees were considered as the statistical sample. In order to gather data, a questionnaire with Cronbach's Alpha 0.89 has been arranged . For the purpose of data analysis SPSS software, Friedman Test, t-Test and Gap Analysis have been applied. The results showed that the state of organizational support, organizational justice and the strategic approach for maintaining human resources are faced with injury.
\end{abstract}

Keywords: Organizational Pathology, Human resources Maintenance System, Strategic Approach, Organizational Commitment

\section{Introduction}

Organizations are subject to constant change from within and outside the organization. By results of research on the role and importance of human resources development, the role of the organizations have been emphasized, that no society has developed unless it has paid

1.akram_ahmadnia@pgs.usb.ac.ir 
enough attention to the development of human resources. Due to this fact, organizational pathology will be useful when its aim is to help management to identify organizational needs and achieve greater opportunities. In this sense, the goal is not to find problems and solve them, but the assessment of current situation and provide a progressive view where evaluating the strengths and resources which are available in the short term, leads to the effective infinite power in the long term. Combining the ideas of strategic management and human resource management make HR to be seen as a strategic resource. With this look to address the issue of maintenance of human resources with strategic approach is a necessity. Since, the organization commitment greatly reduces the cost of relocating employees and improves productivity and employee performance. Therefore, in this study the aim is a pathological status of strategic approach to maintenance human resources and organizational commitment by checking the status of mediator variables affecting organizational commitment.

\section{Literature Review}

Factors such as the nature of the problem, new environmental conditions, related people or chosen information by the Board cause some inefficiency in the management of the organization (Manzini, 1988). The concept of pathology in the organizational development is used similar to that medical pattern. Organizational pathology uses special methods in gathering important information about the organization. This information is evaluated and appropriate organizational intervention is planned (Miles and Charles, 2003). In the pathological process within the organization, the results of the collected data are given to organizational members as a feedback in order to begin the process of organizational change (Falletta, 2008).

Brodeur in an article has pointed to appropriate pathologic features. These features include: "Pathology increases the capacity of firms to change their organizational culture; pathology creates a good opportunity to gain new insights into different aspects of the work, pathology assumes a commitment to continuous improvement." He also suggests that pathology begins when a group (usually management) find out that company has a problem and this problem needs identification (in the point of occurrence) and change and a combination of internal and external forces, start the process of gathering data and information. The process of data collection would lead to the ones which are felt to have accuracy and validity (validity criterion). The results of the collected data are given to organizational members as a feedback to take the correct actions to be implemented». (Brodeur, 2008). Bradley believes that "due to the emergence of new technologies and globalization, actions should be taken to lead the change process, specifically in a competitive environment. Thus, in this competitive environment, innovative industrial structures are needed to respond to these changes and guide these organizational modifications with the creation of organizational forms. It is natural that in all stages, this uncertainty is prevailing and it is necessary to, first; promote our understanding of the global environmental changes in the place where we are competing. Second, we need to improve our effectiveness in the management of innovation (in the era of rapid changes in information), and Third, help to improve the effectiveness of leadership and change management processes in the organization (Bradley, 2008). We propose that organization effectiveness and performance objectives determine the strategic focuses of the organization, and the strategic focus influences the strategic objective of the HR system. In addition, HR systems contribute to organizational effectiveness by enhancing employees' collective performance. This proposition is based on the argument that organizations do not "perform" and that it is the individuals in an 
organization who perform in ways that allow the organizations to achieve desirable effectiveness and performance outcomes (Kozlowski and Klein, 2000). Kidombo (2012) In his research, HR Strategic Orientation and Organizational Commitment in Kenya Manufacturing Firms, sought to investigate the relationship between the soft and hard strategic orientations of human resource management and three components of organizational commitment: affective, continuance and normative. The results showed that a strategic approach to human resources is a significant and positive effect on organizational commitment. Messner (2012)showed that the dimensions of organizational culture on organizational commitment in the IT services industry in India has a significant positive effect. Ayobami (2013) found in his research Significant relationship is between the components of organizational justice, organizational commitment. Glarino (2013) Strategic human resource management have a significant positive relationship with perceived organizational support and job attitudes. Colakoglu (2010)find that perceived organizational support affected on organizational commitment. According to what was stated, in this study, the aim is determine the extent of the gap between current and desired in variables of strategic approach to maintenance human resource system, organizational support, organizational justice, organizational culture, needs of Excellence and organizational commitment.

\section{Questions of the study}

This study seeks to answer the following questions:

- What harms are faced with the strategic approach for maintenance human resource system in the case study?

- How much are the most gaps in the existing and the desired situation key elements that affected by strategic approach in organization?

- What is the current status of maintenance human resource in terms of organizational support in organization?

- What is the current status of maintenance human resource in terms of organizational justice in organization?

- What is the current status of maintenance human resource in terms of organizational culture in organization?

- What is the current status of maintenance human resource in terms of the needs of Excellence in organization?

- What is the current status of maintenance human resource in terms of organizational commitment in organization?

\section{Methodology}

The statistical population of the current research includes Zahedan Municipal employees with the number of 2032. Morgan's table for limited population has been used for determining the minimum required sample volume and 324 persons were considered as the basis of analysis with the use of simple random sampling method.

The research data have been collected with the use of researcher-made questionnaire which consists of 88 questions. The collected data have been analyzed with the use of Likert scale. Thus, the questionnaire tested strategic approach to maintenance human resource system with 12 questions, Organizational Commitment with12 questions, organizational support with 16 questions, organizational justice with 12 questions, organizational culture with 24 questions and needs of Excellence with 12 questions and after localizing with high 
validity (with the approval of elites and experts) and significant reliability0/89using alpha was based on field research.

In the present study, data analysis was performed by SPSS19; descriptive statistical methods to characterize the demographic characteristics of the sample were used. Inferential statistical techniques such as Friedman's test and one-sample t test and the gap analysis were used to identify gaps from the desired position.

\section{Research findings}

To determine a priority in variables Friedman Test was applied. Prioritization of these variables can be seen in Table 2:

Table 1. Friedman test for the prioritization of research variables

\begin{tabular}{c|c}
\hline Number & 258 \\
\hline Chi-square & 1427.907 \\
df & 5 \\
Asymp.Sig & 0.000 \\
\hline
\end{tabular}

Table 2. Variables in order of preference

\begin{tabular}{cc|c}
\hline Row & Variables & Mean ratings \\
\hline 1 & Organizational Commitment & 14.09 \\
2 & Needs of Excellence & 14.06 \\
3 & Organizational Culture & 11.36 \\
4 & Organizational Support & 10.39 \\
5 & Organizational Justice & 9.78 \\
6 & Strategic Approach to Maintenance Human & 9.68 \\
\hline
\end{tabular}

As can be seen in Table 2, in case study organizational commitment most of the rest of variables are taken into consideration and the lowest amount of attention devoted to the Strategic Approach to Maintenance Human Resource in organization.

\section{Results of One-Sample T-Test}

To determine the status of variables in case study one-sample T-test has been applied, the following assumptions were considered in two aspects:

- H0: Target variables mean, is not appropriate.

- H1: Target variables mean, is appropriate.

The results of these tests can be seen in Table 3: 
Table 3. Results of one-sample T-test

\begin{tabular}{|c|c|c|c|c|c|c|}
\hline & \multicolumn{6}{|c|}{ Test Value $=3$} \\
\hline & \multirow{2}{*}{$\mathrm{T}$} & \multirow{2}{*}{$\mathrm{df}$} & \multirow{2}{*}{ Sig(2-tailed) } & \multirow{2}{*}{$\begin{array}{c}\text { Mean } \\
\text { difference }\end{array}$} & \multicolumn{2}{|c|}{$\begin{array}{l}\text { 95\% Confidence Interval } \\
\text { of the difference }\end{array}$} \\
\hline & & & & & Lower & Upper \\
\hline $\begin{array}{l}\text { Organizational } \\
\text { Commitment }\end{array}$ & 16.379 & 323 & 0.000 & 0.541 & 0.4763 & 0.6063 \\
\hline $\begin{array}{l}\text { Organizational } \\
\text { Support }\end{array}$ & 1.60 & 323 & 0.111 & 0.067 & -0.015 & 0.150 \\
\hline $\begin{array}{l}\text { Needs of } \\
\text { Excellence }\end{array}$ & 11.980 & 323 & 0.000 & 0.461 & 0.385 & 0.537 \\
\hline $\begin{array}{c}\text { Strategic } \\
\text { Approach to } \\
\text { Maintenance } \\
\text { Human Resource }\end{array}$ & 1.658 & 323 & 0.098 & 0.761 & -0.014 & 0.166 \\
\hline $\begin{array}{l}\text { Organizational } \\
\text { Justice }\end{array}$ & 1.010 & 323 & 0.313 & 0.046 & -0.043 & 0.136 \\
\hline $\begin{array}{l}\text { Organizational } \\
\text { Culture }\end{array}$ & 5.137 & 323 & 0.000 & 0.217 & 0.134 & 0.301 \\
\hline
\end{tabular}

As seen in Table 3, for organizational commitment $\mathrm{T}=16.379, \mathrm{DF}=323$ and Sig=0.000 and under 0.05 and lower and upper limits are positive, Therefore, the null hypothesis is rejected. As a result, commitment variable mean in research sample is greater than 3 and significant, hence the state of commitment variable is suitable. A significant number of organizational support is1.60 and more than 0.05 , consequently, the null hypothesis is confirmed. The state of organizational support is not suitable. A significant number of needs of excellence are 0.000 and less than 0.05; consequently, the null hypothesis is rejected. So the state of Needs of Excellence is suitable. A significant number of strategic approach to maintenance human resource is 0.098 and more than 0.05 ; consequently, the null hypothesis is confirmed. So the state of strategic approach to maintenance human resource is not suitable. Also according to table, the state of organizational justice is not suitable. And the state of organizational culture is suitable.

\section{Analysis of gaps/ Damages (The gap between existing and desired state)}

Marking options for each variable used in the questionnaire based on Likert 5 option from very strongly disagree (disadvantage) to a much agree (desirable) Coded from 1 to 5 . the number 3 will be the mean and 5 digit will determine desirable for each variable . Thus, by subtracting the mean of each variable (The present situation) from 5, Gap and the damage will be determined, and divided by 5 and multiplied by 100 percent of the gap is determined. The result of the procedure is given in Table 4: 
Table 4. Damages based on priority

\begin{tabular}{|c|c|c|}
\hline Priority of damage & Gap percent & variables \\
\hline The first priority & 39.2 & Organizational Justice \\
\hline The second priority & 38.8 & Organizational Support \\
\hline The third priority & 38.6 & $\begin{array}{c}\text { Strategic Approach to } \\
\text { Maintenance Human } \\
\text { Resource }\end{array}$ \\
\hline The Fourth priority & 35.8 & Organizational Culture \\
\hline The fifth priority & 30.8 & Needs of Excellence \\
\hline The sixth priority & 29.2 & $\begin{array}{c}\text { Organizational } \\
\text { Commitment }\end{array}$ \\
\hline
\end{tabular}

As seen in Table 4, According to the staffs who have responded to the questionnaire the most damage is in the range of organizational justice, the next priority gaps with the desired position are Organizational Support and Strategic Approach. This result, has been approved the result of the $\mathrm{T}$-test was discussed in the last section. Because as obtained in T-test state variables of organizational justice, organizational support, and strategic approach in organization not suitable.

\section{Conclusion}

In this study, the researcher has attempted to look pathologically to variables affecting the maintenance human resource and their status in the organization. The results showed that in organization more attentions are given to three variables of organizational commitment, Needs of Excellence and Organizational Culture than three variables of organizational support, organizational justice and strategic approach to maintenance human resources. It also comes from the results which state,such variables as organizational support, strategic approach to maintenance human resources and organizational justice are not suitable. The organization is in need of more efforts to improve the status of the organization to fulfill these variables. Damage Evaluation and variable distance from the ideal situation are confirmed that the organization is faced with the challenge in the situation of variables organizational justice, Organizational support and strategic approach to maintenance human resources and damages seem in the process of organizing these variables. To deal with these damages the following suggestions are offered:

The orientation of the maintenance of human resource should be in line with best practices communicated and aligned with the organization's overall strategy. Coordinating between policies and strategies of human resource is necessary. So, these two should be complementary and reinforce each other. Continuously, Should be observed process of change in maintenance of human resources system in other organizations. Human resources retain experiences of other organizations exploited. Keeping the experiences of others, the organization should be a place that has a unique compensation system and provide the context necessary to excellence and providing spiritual rewards for its employees. Compared to other organizations provide the greater prestige for its employees. Organization attaches more value to each of its employees. Respect to their beliefs and shows importance to them progress of work. If them experience problems does not hesitate to help them. Prioritize importance to the welfare and satisfaction of employees. When taking important decisions to move and changes in the activities of employees, the benefits are also concerned. The employee does not feel 
agencies wherever necessary win waived his interests and at any minute replace him with another person. Employee must not feel that his voice is not heard in the organization and one does not matter his wishes. The organization must appreciate the efforts that employee cares. Organization must use fair procedures for evaluating the performance of employees and their actions will only consider. Accordingly, uniformly regulate compensation practices. Shall apply uniformly among its employees equity and fairness. So that should be proportional distribution utilities and facilities, rights and privileges and distribution points based on their performance and accountability. Responsible for each part of the organization should make efforts to have the behavior with their subordinates sincere, honest, courteous and respectful.

\section{References}

Ayobami, P. (2013). Impact of Perceived Organizational Justice on Organizational Commitment of a Food and Beverage Firm in Nigeria. International Journal of Humanities and Social Science, Vol. 3, No. 14, Special Issue - July.

Bradley, Stephen P, Pfizer,( 2008), Leadership Development Program, Harvard Business School, Journal of Interactive Marketing, spring.

Colakoglu, U. Culha, O., Atay, H.(2010).The effects of perceived organizational support on employee' s affective outcomes: Evidence from the hotel industry, Tourism and Hospitality Management, Vol. 16, No.

2, pp. 125-150.

Falletta, Salvatore V, (2008), "HR Intelligence: Advancing People Research And Analytics", IHRIM journal, Vol. XII, No. 3.

Glarino, G.(2013). Strategic Human Resource Management: Influences on Perceived Organizational Support and Job Attitudes, International Journal of Business and Social Science, Vol. 4 No. 12 ,Special Issue September.

Kidombo, H., K’Obonyo, P., Gakuu, C. (2012). Human resource strategic orientation And organizational commitment in Kenyan manufacturing firms, International Journal of Arts and Commerce, Vol. 1 No. 7, December.

Kozlowski, S.W.J., and Klein, K. J. (2000). A multilevel approach to theory and research in organizations: Contextual, temporal, and emergent processes. In: K. J. Klein and S. W. J. Kozlowski (Eds), Multilevel theory, research, and methods in organizations: Foundations, extensions, and new directions (pp. 3-90). San Francisco, CA: Jossey-Bass.

Lepak P. David. (2006). A Conceptual Review of Human Resource Management System in Strategic Human Resource Management Research, Research in Personnel and Human Resources Management, Volume 25, 217-271.

Manzini. Andrew O, (1988), Organizational Diagnosis: A Practical Approach to Company Problem Solving and Growth, Published by AMACOM, American Management Association, ISBN 0814457789, 9780814457788.

Messner, W.(2012). Effect of organizational culture on employee commitment in the Indian IT services sourcing industry, Journal of Indian Business Research, Vol. 5 No. 2.

Miles Raymond E, Charles C Snow, (2003), "Organization Adaption", ISBN 0-8047-4840-3. 